\title{
A crítica radical de Espinosa como autoproblematização
}

Dario Galvão

\section{Resumo:}

Pode-se ler que, em sua principal obra, a Ética: demonstrada segundo a ordem geométrica, Espinosa se vê obrigado a explicar como é possível a ideia da transcendência se originar do mundo da absoluta imanência. O problema central abordado neste trabalho é colocado com a inversão dessa pergunta: como, no seio de um mundo transcendente, ou seja, um mundo que toma a transcendência como princípio fundamental de explicação da vida em sua totalidade, faz-se possível surgir a ideia da imanência, seu oposto e contraditório? Dessa forma, buscamos compreender as condições de possibilidade da crítica radical espinosana à tradição. Para isso, procura-se fazer um exame dos elementos constitutivos desse movimento crítico, com o qual veremos a necessidade de ser considerada a experiência, a partir da ideia de autoproblematização, para um entendimento mais rico da questão.

Palavras-chave: Espinosa - Ética - autoproblematização 
Cada ação individual, cada modo de pensar individual provoca horror; é impossivel calcular o que justamente os espíritos mais raros, mais seletos, mais originais da história devem ter sofrido pelo fato de serem percebidos como maus e perigosos, por perceberem a si próprios assim.

(Nietzsche, Aurora $\$ 9$ )

Seria impossível calcularmos o que sofreu Espinosa no decorrer de sua vida. Como Nietzsche parece nos sugerir no trecho acima, é bem provável que não haja régua conveniente para tal avaliação. Espinosa escreve no Tratado da emenda do intelecto sobre uma doença terminal, um estado de proximidade com a morte contra a qual lutava com todas as suas forças (ESPINOSA, I973, $\$ 7)$. Se não podemos compreender por completo seu sofrimento, ao menos deveríamos ser capazes de nos aproximar desse entendimento. Por que não perguntar: afinal, o que sofreu Espinosa?

Alguns fatos podem nos ajudar: excomunhão do judaísmo aos 24 anos, com promulgação em tom odioso como "maldito seja de dia e maldito seja de noite, maldito seja em seu deitar e maldito seja em seu levantar". ${ }^{\mathrm{I}}$ Exclusão espiritual, que na época representava também exclusão política e econômica. Não se saía do meio religioso sem sair do econômico, de modo que Espinosa foi obrigado a abandonar os negócios do pai. E conforme desenvolve sua obra filosófica, a exclusão é sofrida até mesmo no universo científico. Podemos ver esse processo de exclusão como consequência da "ação individual" e do horror que ela provoca, como Nietzsche nos aponta. Espinosa buscava a ruptura, eis um importante elemento para entendermos seu sistema filosófico.

Sem dúvida, a produção de Espinosa incomodou profundamente toda a civilização ocidental. Teses explícitas de sua principal obra, a Ética: demonstrada segundo a ordem geométrica, abalaram fundamentos seculares cruciais à tradição judaico-cristã. Alicerces responsáveis pela organização de toda a experiência até então. O filósofo refuta teses como a existência de um deus transcendente, ser externo ao mundo, que seria responsável pela criação e ordenação contínua deste e sobre o qual possuiria total liberdade de atuação e interferência. Essa refutação é um exemplo, e talvez o mais fundamental, da desorganização que a filosofia de Espinosa traz à sociedade à qual pertence.

I Herem - anátema - pronunciado contra Espinosa, em 27 de julho de I656. Informação encontrada no texto de orelha da edição de Ética, publicada pela editora Alternativa, em 20IO, com tradução de Tomaz Tadeu. 
É precisamente pela radicalidade da crítica à cultura que a filosofia de Espinosa sofre dura resistência de seus contemporâneos. Ela atinge ideias que dirigem o modo como o homem se relaciona com o mundo, em seu sentido mais íntimo. Trata-se de um ataque totalizante ao modo de interpretação desse mundo, comum à longa tradição ocidental. Abala princípios que sustentam sua dotação de sentido e todas as suas valorações. São ideias não aparentes que, de tão enraizadas na cultura, moldam a experiência mesmo daqueles que acreditam não compartilhá-las. É então forjada a imagem do filósofo: um monstro do qual todos devem se manter longe, protegidos e a salvo.

Que forças se digladiam no interior daquele que se recusa a acatar normas do grupo ao qual pertence em benefício de uma investigação acerca da própria individualidade? É razoável pensar que esse movimento de renúncia ao todo pode acontecer em diferentes graus nos diferentes indivíduos. Inclusive, é possível que homem algum possa livrar-se por completo dessa tensão. Entretanto, deve-se atentar para a particularidade de Espinosa nesse processo: a radicalidade de sua crítica. O filósofo faz oposição a verdades inquestionáveis e mostra erro e fraqueza naquilo em que a tradição se considerava mais forte.

É a respeito das condições de possibilidade dessa crítica radical que trataremos nesse texto. Buscaremos compreender como Espinosa é capaz de efetivar tamanha crítica às raízes da cultura, na qual ele próprio foi constituído. Se toda produção de saber é determinada por essas raízes e, sobretudo, se a própria possibilidade da experiência do mundo passa por essa espécie de "grelha comum de compreensão", como é possível abalar seus alicerces? Como fazer a crítica dos fundamentos da tradição, se toda forma de pensamento e, portanto, de crítica, passa necessariamente por eles? Qual é o ponto de apoio de Espinosa?

Podemos colocar esse mesmo problema partindo de dois conceitos opostos da leitura da filosofia crítica espinosana: a imanência e a transcendência. O mundo imanente é completo e dotado de plenitude em si mesmo, organizado a partir de seu interior. No transcendente, o princípio ordenador do mundo está além ou fora dele. Pode-se ler que, ao defender a tese de Deus imanente ao mundo, Espinosa se vê obrigado a responder "como e por que um universo da imanência absoluta dá origem em seu seio [...] à transcendência, que é seu antípoda?" (SANTIAGO, 2009b; grifo nosso). A resposta é dada no "Apêndice I" da Ética e não nos interessa tanto quanto a pergunta. Para esse texto, é relevante pensar o problema pela inversão dessa pergunta: como no seio de um mundo ao qual Deus é transcendente, ou seja, um mundo que toma a transcendência como princípio fundamental de explicação da vida em sua totalidade, é possível surgir a ideia da imanência, seu oposto e contraditório? 
Pensarmos sobre as condições de possibilidade da crítica radical espinosana, interior à cultura, é pensarmos como a ideia da imanência pode ser produzida e, o mais importante e complicado, como ela pode transformar a experiência. Uma forma de solucionar esse problema seria considerarmos que Espinosa opera um escape da totalidade da ordem da tradição e, assim, torna possível a denúncia da falsidade daquilo que se diz por verdadeiro.

No entanto, a ideia de que é necessário escapar da totalidade da ordem da tradição para fazer a crítica é equívoca. É um pensamento superficial, que se mostra incoerente em suas consequências. A crítica total espinosana deve ser compreendida como interior à cultura, apesar das dificuldades de pensá-la como tal. Como é possível conceber um homem absolutamente fora de sua cultura? Para imaginarmos isso, teríamos que considerar uma total incomunicabilidade entre Espinosa e seus contemporâneos, o que é absurdo. Espinosa se apropria da linguagem e do modo de pensar comuns a seu tempo, e somente a partir disso opera a crítica, a transformação.

Evidentemente, podemos pensar que Espinosa se coloca em uma certa exterioridade em relação ao senso comum, seja dos valores da vida ordinária, seja da sociedade científica. Entretanto, há algo no interior da cultura de que Espinosa se utiliza para a construção de sua nova forma de vida, explicitada na Ética. A crítica radical ocorre em um processo de questionamento dos pilares da civilização, a partir de uma investigação de si mesmo, em um movimento que chamaremos de autoproblematização. Com a ajuda dessa noção, a dificuldade de pensarmos a crítica radical interna dissolve-se. Existe a possibilidade da criação de uma nova forma de interpretação e valoração, ou seja, de uma nova forma de vida, que emerge de um processo de autorreflexão. $O$ indivíduo, então, seria capaz de enxergar um jogo de tensão inerente aos pilares, abalá-los e reorganizar toda a experiência.

A questão levantada no começo deste texto, a respeito do sofrimento daquele que se opõe a velhos ideais e tenta produzir uma nova forma de vida, servirá para melhor compreendermos a dinâmica da autoproblematização. O sofrimento do "pensar individual" mostra-se consequência de um conflito não apenas na relação com outros homens, mas também na relação consigo mesmo. O movimento de perceber a si próprio como mau e perigoso, indicado por Nietzsche, nos evidencia que aquele que cria o novo não o faz sem que, ao mesmo tempo, ele próprio seja destruído. O novo se dá a partir do antigo, num duplo movimento de destruição e construção. Há uma tensão contínua na experiência da crítica, expressa no conflito entre os ideais individuais e os coletivos. Ao pensar na individualidade, Espinosa causa horror a si mesmo, pois a tradição o constituiu para sentir horror a toda manifestação de 
individualidade. Trata-se de um jogo extremamente perigoso em que o risco de vida torna-se iminente.

O presente texto possui dois momentos. No primeiro, procuraremos explicar a possibilidade de realização da crítica radical a partir de dois elementos centrais da filosofia de Espinosa: a norma de verdade das matemáticas e o ideal de natureza humana mais firme. Ao final dessa exposição, notamos a insuficiência da consideração do problema nessa perspectiva. No segundo momento, procuramos suprimir essa insuficiência ao inserir a dimensão da experiência a partir da ideia de autoproblematização.

\section{Pontos de apoio da crítica}

O projeto espinosano é fortemente determinado pela resposta a um profundo "para quê?", que se mostra na forma de um ideal de natureza humana. Esse elemento em momento algum deixa de operar no interior da crítica e, sobretudo, parece determinar a direção de todo o esforço crítico.

No Tratado para emenda do intelecto, Espinosa escreve a respeito da finalidade de sua filosofia: "o fim ao qual tendo: adquirir uma natureza humana assim" (ESPINOSA, I973, \$I4), uma "natureza humana muito mais firme" (ibidem, \$I3). Para o filósofo, a partir do momento que o homem concebe como atingível uma natureza mais firme que a sua, o fim de toda ação humana deve ser a realização do aumento de firmeza de sua própria natureza.

Não se trata de um ideal utópico, mas de um ideal de superação individual. Não diz respeito a uma natureza humana em geral, mas a uma natureza humana de cada indivíduo, de tal forma que os caminhos para o aumento de força só podem ser entendidos para cada singularidade. É para o aumento de felicidade (que pode ser vista também como liberdade e beatitude) que tende toda a filosofia de Espinosa. Essa busca figura-se como o novo princípio organizador da reflexão filosófica para Espinosa e, portanto, de sua crítica radical.

Ora, se o problema que antes de todos Descartes se coloca é o problema da certeza na ciência, o problema que antes de todos Espinosa se coloca é o problema da saúde da alma, da verdadeira liberdade e da beatitude (DELBOS, 2002, p. 20).

Espinosa não se mobiliza para encontrar no mundo o caminho para a verdade científica, uma certeza indubitável, uma pedra fundamental sobre a qual todo o conhecimento humano seria reformado e reerguido, o grande edifício 
da ciência. Para ele, todo problema que não sirva para a busca da felicidade do homem não merece atenção. O seu problema fundamental é o problema ético: o que fazer para ser feliz?

Assim, o filósofo invoca a atenção e o trabalho intelectual para a busca pelo conhecimento da natureza humana, em vista de apreender as condições necessárias para realizar as potencialidades inerentes a tal natureza. É natural que todo o projeto crítico de tamanha radicalidade possua, por conseguinte, alto grau de incerteza em relação àquilo para o que se é lançado. Não se sabe muito sobre o novo quando ainda habita-se o solo antigo. A busca espinosana inevitavelmente adquire essa condição de incerteza. Então, cabe a pergunta: em que conhecido apoia-se Espinosa para ir rumo ao desconhecido, ao novo?

Seria a matemática uma resposta suficiente a essa pergunta?

No "Apêndice I" da Ética, Espinosa escreve que se não fosse a "outra norma de verdade" (ESPINOSA, 20IO, p. 67) mostrada pela matemática, os homens permaneceriam para sempre na ignorância. ${ }^{2}$ Não é difícil perceber o importante papel da matemática no pensamento espinosano e em toda a sua obra. A Ética, a principal delas, é feita a maneira dos geômetras, com definições, axiomas, proposições e demonstrações no tradicional estilo euclidiano. Vê-se que a matemática propicia um certo "despertar filosófico": denuncia o conhecimento falso da ignorância e aponta o caminho do conhecimento verdadeiro.

É inegável a natureza de fundamento que a matemática tem na filosofia de Espinosa. Entretanto, para entendermos como ocorre essa fundamentação é necessário compreendermos o que Espinosa quer dizer com norma de verdade. É a ela que se atribui a valor de fundamentação, e não à matemática em geral.

A matemática possui uma função pedagógica. Ela nos ensina um modo de pensar específico. Todo tipo de conhecimento, para Espinosa, deve alimentar-se de algo do conhecimento matemático. Uma apropriação não das verdades que ela traz, nem de sua aplicação incondicional a uma compreensão rigorosa da natureza, que se tornaria "matematizada". Não isso, mas uma aprendizagem a respeito de uma postura, de um procedimento epistemológico. O valor da matemática para o movimento crítico espinosano está na didática do pensamento.

2 "Essa razão [a tese da infinita superioridade do juízo dos deuses] teria sido, sozinha, realmente suficiente para que a verdade ficasse para sempre oculta ao gênero humano, se a matemática, que não se ocupa de fins, mas apenas de essências das figuras e de suas propriedades, não tivesse mostrado aos homens outra norma de verdade" (ESPINOSA, 20I0, p. 67). 
Trata-se de uma disciplina que "não se ocupa de fins, mas apenas de essências das figuras e de suas propriedades" (ibidem). Ela trabalha com definições reais e genéticas de seus objetos. Conhecer é conhecer pela coisa em si ou por suas causas (ESPINOSA, I973, \$ig). O matemático é um homem que sabe pensar de maneira não finalista. O conhecimento de uma figura geométrica não envolve, em momento algum, a causa final, aquilo para o que a coisa tenderia ou deveria tender. Ou seja, o conhecimento não envolve uma ideia de fim que estaria presente na essência do objeto de estudo.

O pensamento não finalista que Espinosa apreende da matemática e aplica sobre a questão ética do ser humano é extremamente contraditório ao pensamento vigente no século XVII, no que diz respeito ao âmbito da moral. Esta, sustenta-se na afirmação de um conhecimento finalista a respeito do homem. Para a tradição religiosa, o homem é um ser que nasceu para cultuar os deuses e, com base nisso, há todo um sistema ético.

Com a matemática, Espinosa aprende a pensar a essência de cada coisa conforme ela é, e não conforme se quer que ela seja. Como esclarece Marilena Chaui, opera-se uma verdadeira "construção intelectual de seus objetos", analisando as causas eficientes ("maneira como são produzidos") e suas propriedades (CHAUI, p. 37). Um quadrado é como ele é, um quadrado. Não se aplica sobre o quadrado qualquer espécie de valoração finalista, como se o quadrado pudesse ser, por exemplo, um círculo.

Segundo o próprio filósofo, sua intenção na Ética é tratar do homem e de Deus como se estivesse tratando de triângulos e círculos. Isso significa dizer que:

[...] deles oferecerá definições reais, dando-nos a conhecer apenas pelo intelecto, suas causas e efeitos necessários, sua origem e a maneira como suas essências e existências são produzidas (ibidem, p. 38).

Interpretemos o que acontece aqui: Espinosa acredita que o conhecimento rigoroso de si é um meio potente e, sobretudo, o mais eficaz para a realização da perfeição da natureza humana. Segundo a tradição, a natureza humana possui a marca essencial da servidão a Deus acima de tudo. Para refutar isso, Espinosa precisa destruir toda uma forma de saber que, segundo ele, refugia-se na ignorância (ESPINOSA, 20IO, apêndice I), e propor uma nova forma de conhecimento de si e do mundo, apropriando-se da norma de verdade da matemática.

Vemos aí o duplo movimento do projeto ético espinosano: a denúncia de um tipo de conhecimento falso, que leva à submissão e à ignorância; e a afirmação de um tipo de conhecimento verdadeiro, que leva à realização 
da suprema felicidade humana. Nessa perspectiva, a matemática nos aparece como forte candidata para solução de nossa pergunta sobre as condições de possibilidade da crítica radical.

$$
* * *
$$

Aqui, chegamos a vislumbrar a primeira tentativa de solução do problema das condições de possibilidade da crítica. A crítica poderia ser radical e interior à cultura da seguinte forma: o filósofo acorda um dia insatisfeito com a ordem vigente, deseja algo diferente, uma forma de vida completamente nova, e encontra na matemática um caminho para essa transformação. A matemática é um instrumento que lhe está disponível no interior da cultura. Apoiado em um modo de pensar matemático, o filósofo refutaria toda a visão ética vigente e construiria algo novo em seu lugar.

Ficarmos satisfeitos com essa hipótese, no entanto, seria cometer um crime contra a filosofia de Espinosa. Seria perder toda a sua riqueza e contentarmo-nos com uma análise superficial que, talvez, no final deste texto, poderíamos concluir como equívoca.

Onde se encontra, nessa hipótese, a consideração de todo aquele sofrimento inerente à condição do indivíduo crítico, que tratamos na introdução? O enorme sofrimento, que Espinosa coloca como uma "doença terminal" (ESPINOSA, I973, \$7), não nos apontaria para uma série de impeditivos no processo de crítica radical? Não deveríamos, então, procurar pelas condições de possibilidade da crítica também na dinâmica do sofrimento?

Sem dúvida, parte de nossa resposta encontra-se na matemática e na reflexão sobre a possibilidade de realização de uma natureza humana mais firme. Todavia, precisamos ir além. A crítica espinosana não é suficientemente compreendida a partir desses dois elementos. O problema é mais complexo do que um simples despertar filosófico, segundo o qual a possibilidade da crítica viria de um caminho claro e evidente, como decisão de uma vontade que age sem limitações, ou seja, que tudo pode e vai para onde bem entender. As condições de possibilidade da crítica devem ser investigadas no interior da experiência do indivíduo. É lá que realmente acontece a crítica.

Questionemo-nos, portanto, pela experiência vivida pelo indivíduo crítico. Nela, a norma matemática torna-se um elemento dentre outros atuantes. Apesar de não perder seu estatuto de fundamentação da crítica, possivelmente ela deixa de ser o único ponto de apoio, já que a própria experiência será também responsável por grande parte do material mobilizado na crítica, tanto negativa como positivamente. A experiência mostrará problemas evidentes no 
modo de vida da tradição, ${ }^{3}$ assim como mostrará caminhos que podem ser seguidos para a construção de uma nova forma de vida. Certamente, a construção do novo modo de vida, em Espinosa, não se limita ao pensamento matemático. Antes disso, Espinosa empenha-se na construção de uma melhor forma de se estar no mundo, um modo de ser feliz.

Seria possível assinalar, além da matemática, ainda outras razões (seria supérfluo enumerá-las aqui) que podem ter levado os homens a tomarem consciência desses preconceitos comuns, conduzindo-os ao verdadeiro conhecimento das coisas (ESPINOSA, 2010, p. 67).

O filósofo fala sobre "outras razões", além da matemática, que poderiam levar os homens a uma tomada de consciência. Em seu texto "O fllósofo espinosista precisa criar valores?", Homero Santiago defende que a experiência deve ser compreendida como uma dessas outras razões. Apesar de reconhecer a dificuldade de assumirmos que a experiência ensinaria uma norma de verdade como a da matemática, Santiago não deixa de colocar um peso muito significativo à experiência na realização da crítica espinosana. ${ }^{4} \mathrm{De}$ tal forma que corremos o risco de sermos superficiais se fizermos uma reflexão sobre a crítica sem dar a devida atenção a ela.

A nosso ver, na coadunação da matemática com essas outras causas reside o mais profundo de nosso problema, que é menos a própria negação [do sistema explicativo da tradição] que a sua condição de possibilidade: como um homem pode conseguir, nem digamos negar, mas tecer um questionamento que torne pensável algo diferente da superstição dada? (SANTIAGO apud MARTINS, 2009a, p. I99).

Santiago parece nos apontar um caminho para solução de nosso problema. Ele nos mostra que, em Espinosa, para pensarmos as condições de possibilidade da produção de uma nova forma de pensamento, devemos investigar não só a matemática, mas também essas "outras razões", nas quais a experiência deve ser incluída. ${ }^{5}$

3 Sobre isso, ver o tema "O protesto da experiência" em SANTIAGO, 2007a, p. I37.

4 "É difícil dizer que a experiência ensine uma norma de verdade (como a matemática), mas nos dois casos importa é que ela nos force a 'abrir os olhos' para a incoerência e quiçá a falsidade do sistema em que estamos e no qual acreditamos [...]." (SANTIAGO, 2007a, p. I38)

5 Neste texto faremos como Santiago no texto citado, trataremos apenas da experiência no que concerne a essas "outras razões". 


\section{A autoproblematização}

Qual seria, então, a dinâmica interna desse movimento crítico radical?

Entretanto, não é sem razão que usei destes termos: se pudesse seriamente deliberar. Porque, ainda que percebesse mentalmente essas coisas com bastante clareza, nem por isso podia desfazer-me de toda a avareza, concupiscência e glória (ESPINOSA, I973, SIO).

Nesse trecho, Espinosa nos mostra algo muito importante para a continuação deste texto. $\mathrm{O}$ movimento crítico, que pode ser entendido como um movimento de transformação, não decorre facilmente de uma simples decisão de transformar-se. Ainda que o filósofo perceba que o que é tido como "bem" na vida comum, é, na verdade, um "mal", o movimento de negação desses valores é algo muito difícil. Livrar-se por completo da avareza, concupiscência e glória, bens compreendidos na vida comum, significa livrar-se de sua própria natureza, daquilo que o constitui inclusive durante seu processo crítico. Segundo Espinosa, no $\$ 3$ do Tratado, a busca pelo bem verdadeiro é impossível se permanecemos presos aos bens da vida comum, que se mostraram como males. Entretanto, o antigo não pode ser simplesmente deposto de imediato, por força da vontade. Diante disso, como prosseguir na crítica?

A dinâmica da crítica interna ao indivíduo deverá acontecer num duplo movimento: destruição daquilo que não se considera mais interessante para a vida e construção de um novo edifício sobre o qual se viverá. É um processo de busca pelo aumento de potência, ainda que se tenha o novo como incerto. A crítica, dessa forma, mostra-se como uma experiência do afastamento do "comum". O indivíduo encontra um descompasso entre o que lhe é dito na tradição e a sua experiência.

Esse descompasso perturba, faz duvidar, suspeitar e, no limite, sugere uma novidade, ao menos a possibilidade de se construir algo novo. Um abalo (mais ou menos violento) na estrutura a que nos encontramos presos (e a consequente incerteza quanto ao futuro no interior dela) acarreta um desprendimento paulatino com relação a tal estrutura, que no Tratado da emenda tem o nome de "vida comum". É desprendendo-se da vida comum e de seus grilhões que se pode pensar algo novo (SANTIAGO, 2007a, p. I38).

Começamos a nos aproximar de um entendimento que explicaria a possibilidade do surgimento de uma nova forma de vida, sem cairmos na ideia de que 
se daria a partir do nada, ex nihilo. Nos parece necessário procurá-la naquilo que chamamos de solo antigo, ou seja, na forma de pensar anterior à crítica. Vejamos agora como se passa esse movimento de autoproblematização, no qual abre-se uma possibilidade para reorganização radical da própria forma de pensar. Entender esse movimento é entender as condições de possibilidade para a crítica radical espinosana.

Essa inflexão de sentido ou mudança de direção caracteriza-se como uma volta contra si mesmo, uma reflexão, e, nesse sentido, uma inversão de rota, um dobrar-se sobre si mesmo, tornado possível por problematização, ou seja, por um voltar-se para si mesmo (e contra si mesmo) do próprio sujeito ou de um processo histórico no interior do qual o primeiro se encontra, que, de diferentes maneiras, tomam a si mesmos como objeto - o que caracteriza, portanto, um movimento de (auto) problematização (GIACÓIA Jr., 20IO, p. 76).

Esse trecho encontra-se no texto de Oswaldo Giacóia Jr., Autossupressão como catástrofe da consciência moral, onde ele escreve sobre o conceito de autossupressão no pensamento nietzschiano. Com esse conceito, Nietzsche mostra que toda grande forma de interpretação, ou toda moral, perece por si mesma, "assim quer a lei da vida, a lei da necessária "autossuperação" que há na essência da vida" (NIETZSCHE, I998, III, \$27).

Por que não aproximarmos a experiência de Espinosa a esse conceito nietzschiano? Giacóia fala em "autossupressão como catástrofe da consciência moral", podemos associar essa colocação com o problema vital que Espinosa sofre ao realizar sua crítica e solapar os pilares ético-morais da tradição da qual ele próprio foi constituído. Não estaria Espinosa experimentando a catástrofe de sua consciência moral?

Giacóia fala também em uma experiência da vertigem (GIACÓIA Jr., 20IO, p. 84) inerente a essa catástrofe. Poderíamos encontrar uma experiência da vertigem em Espinosa em seus depoimentos a respeito do problema vital, quando se vê no estado de "um doente, atacado de fatal enfermidade, que antevê morte certa se não encontra um remédio da doença" (ESPINOSA, I973, \$7). A vertigem pode ser encontrada na experimentação espinosana de destruição dos pilares e na aparição de um vazio que, a muito custo, é substituído. Esse vazio continua a assombrar o filósofo durante períodos maduros da crítica, uma vez que, como vimos, livrar-se dos preconceitos antigos não é fácil.

Difícil não pensarmos nas semelhanças com a crítica espinosana, quando Giacóia escreve que a autossupressão da moral em Nietzsche envolve o ato 
[...] de afrontar a moral como um problema, de abalar os alicerces da crença na moral, de impugnar seu direito a essa crença. [...] [Faz-se] aqui a experiência crucial do desligamento em relação à própria moralidade (GIACÓIA Jr., 20IO, p. 87-88).

Certamente, essa aproximação entre o conceito de autossupressão da moral em Nietzsche, interpretado por Giacóia, e o processo da crítica radical em Espinosa, é merecedora de um estudo mais aprofundado. Todavia, não pretendemos explorar essa seara aqui. Basta nos atermos à ideia de autoproblematização. Interpretemos a crítica espinosana à luz dessa noção.

Ponderava, portanto, interiormente se não seria possível chegar ao novo modo de vida, ou pelo menos à certeza a seu respeito, sem mudar a ordem e a conduta comum de minha existência, o que tentei muitas vezes, mas em vão (ESPINOSA, I973, §3).

A ideia de autoproblematização expressa muito bem o cerne da filosofia espinosana. Autoproblematização é "tomar consciência de si mesmo como um problema" (GIACÓIA Jr., 20Io, p. 76). Ocorre em um movimento de retorno a si, com o qual, a partir da objetivação de si mesmo, promove-se uma descrença absoluta em relação aos mais profundos princípios de funcionamento da própria experiência. Por isso, a dificuldade do processo, o problema vital, o estado no qual se percebe por doente. Tanto em Nietzsche quanto em Espinosa, vemos que se trata de uma mudança radical de direção que ocorre no interior do ser, de dentro para dentro.

Podemos encontrar em Marilena Chaui a leitura da autorreflexão como elemento constituinte do pensamento espinosano. Segundo ela, o Tratado da emenda do intelecto

[...] consiste, antes de mais nada, em fazer com que nosso intelecto se conheça a si mesmo [...]. Trata-se de um caminho reflexivo, pois nele o intelecto realiza uma reflexão, voltando-se sobre si mesmo para conhecer-se como capacidade inata de conhecimento verdadeiro (CHAUI, 2005, p. 35).

Entretanto, em Espinosa, e isso também se aplica à ideia de autossupressão, a natureza do processo de autoproblematização não se limita à experiência da descrença absoluta. Há necessariamente uma elevada crença em outro princípio, uma intensa confiança. É em nome de alguma coisa que se promove a destruição. Podemos identificar, em Espinosa, o ideal de natureza humana e a forma de pensar da matemática como exemplos de elementos que sofrem essa valorização no interior do processo crítico. 
Vemos, assim, que a autoproblematização está além de uma simples dúvida em relação à realidade. Ela representa uma autêntica experimentação do que podemos chamar de atitude filosófica, cujo momento inicial, é exposto de forma didática no Tratado. Entra-se inevitavelmente em um problema vital. É então que se executa uma profunda reorganização da malha que conforma as condições de possibilidade da experiência. Abala-se a configuração antiga e surge o campo do possível.

Nós ainda não sabemos para onde somos impelidos, depois de nos termos desligado, dessa maneira, de nosso antigo solo. Mas esse mesmo solo criou força que agora nos impulsiona para longe, para a aventura pela qual somos lançados no infinito, no não povoado, não descoberto - não nos resta nenhuma escolha: temos que ser conquistadores, desde que não temos nenhuma terra que gostaríamos de "preservar". Não, isso vós o sabeis melhor, meus amigos! O oculto "sim" em vós é mais forte que todo "não" e "talvez", de que são doentes e dependentes vós e vosso tempo; se tendes de partir para o mar, vós imigrantes, a isso vos obriga uma crença... (NIETZSGHE apud GIACÓIA Jr., 20Io, p. 86).

Sim, há muitas semelhanças entre os pensamentos desses dois filósofos. Assim como em Espinosa, no trecho de Nietzsche podemos ver a força de uma grande afirmação por trás da reflexão filosófica, que, aqui, confunde-se com a experiência do indivíduo : é a vida. Toda negação e destruição se dá na medida e na forma em que a afirmação da vida as requerem.

Entre outras coisas, esse trecho nos mostra que a "força [...] pela qual somos lançados no infinito, no não povoado, não descoberto" é proveniente "de nosso solo antigo". A transformação se dá a partir de uma intervenção no modo antigo de ser, na qual provoca-se um abalo, uma brecha, fissuras sobre as quais debruça-se intensamente, rasga-se a malha antiga e costura-se novas possibilidades, novas formas de pensar, novas formas de vida.

\section{Conclusão}

A pergunta pelas condições de possibilidade de uma crítica radical e interna à própria cultura mostrou-se, ao longo do texto, uma pergunta de múltiplas faces. Ao colocá-la, perguntamos também: como instituir uma nova forma de vida a partir da tradição? Como é possível a gênese de um pensamento diferente a partir de um comum? Em suma: como uma nova forma de pensar pode surgir da antiga? 
No caso de Espinosa, vimos que a crítica se pretende radical desde o começo. Entretanto, o filósofo se vê incapaz de negar de uma só vez todo o material da tradição, responsável por sua formação enquanto indivíduo. Vimos que para entender a crítica, não podemos nos ater simplesmente ao elemento negativo (aquilo que deve ser destruído) e ao positivo (aquilo que deve ser construído). O movimento crítico real, na vida, não funciona como a matemática. Para o entendimento das condições de possibilidade da crítica, é necessário considerar todo o jogo de forças interno àquele que a realiza.

Em tal reflexão, a ideia de autoproblematização, trazida de Giacóia em sua análise da filosofia nietzschiana, nos foi muito útil. A partir disso, pudemos ir além da consideração ingênua da crítica apenas como um processo movido por um ideal e construída sobre um ponto de apoio. Admitimos a enorme insuficiência dessa consideração em relação ao problema das condições de possibilidade. É na dinâmica interior de sua vida que encontramos os verdadeiros desafios que colocam em risco a efetivação da crítica. Encontramos a difícil tarefa de livrar-se dos preconceitos comuns, que formaram o crítico até o momento de seu "despertar filosófico".

Chegamos à resposta sobre as condições de possibilidade com a contemplação de um movimento de profunda reorganização da experiência individual. A problematização de si é feita com a desconfiança em relação a certos aspectos da própria individualidade, assim como a confiança em outros. Espinosa descarta toda a visão ética da tradição, calcada na ideia de um Deus transcendente e orienta-se para a realização de uma natureza humana mais firme, mais forte, livre e feliz. O filósofo confia na possibilidade do aumento da felicidade, pois, afinal, esta não lhe era totalmente estranha em sua vida anterior à crítica. É provavelmente uma sutil felicidade que experimentava no interior de uma vida majoritariamente difícil, que abre o olho de Espinosa para a possibilidade de experimentar uma vida com mais alegria e menos tristeza e servidão.

A ideia de autoproblematização é importante pois nos permite pensar a realização da crítica radical, não a partir de uma exterioridade absoluta em relação ao objeto criticado, mas a partir de seu íntimo. Quanto mais domina-se o modo de funcionamento desse interior, maiores são as ferramentas para a efetivação da mudança. É inevitável que a crítica se dê apoiada sobre os mesmos pilares que irá derrubar. Afinal, o que não está apoiado sobre tais pilares? É possível pensarmos em algo no interior da cultura que possa ser utilizado contra ela própria? Sim! A exploração dos pilares, realizada na própria exploração de si, evidencia tensões internas, contradições e caminhos alternativos possíveis. 
Espinosa utiliza sua própria experiência, calcada no solo antigo, para procurar novos modos de vida. Utiliza também o pensamento matemático, presente na tradição, como arma que lhe possibilita tanto destruir como construir. Elementos presentes na experiência do indivíduo são a matéria-prima da crítica. A experiência prossegue num movimento crítico em relação à própria experiência. Cada vez aproxima-se mais daquilo que se busca. Brechas e fissuras são abertas no interior do solo antigo. A vida é transformada e todas as significações antigas adquirem um novo valor. Não é o mundo que muda, mas a relação do indivíduo com ele. Nada muda, mas tudo muda. Aquele antigo servo passa a experimentar impulsos e clarões de liberdade, autodomínio e inserção na natureza de forma mais verdadeira.

\section{Referências bibliográficas}

CHAUI, Marilena de Souza. Espinosa: uma filosofia da liberdade. São Paulo: Editora Moderna, 2005.

DELBOS, Victor. O espinosismo: curso proferido na Sorbonne em 1912-I913. Trad. Homero Santiago. São Paulo: Discurso Editorial, 2002.

DELEUZE, Gilles. Espinosa: filosofia prática. Trad. Daniel Lins e Fabien Pascal Lins. São Paulo: Escuta, 2002.

ESPINOSA. Ética. Trad. Tomaz Tadeu. Belo Horizonte: Alternativa, 2010. . Pensamentos metafísicos; Tratado da correção do intelecto; Ética; Tratado político; Correspondência. Vários tradutores. São Paulo: Abril Cultural, 1973. (coleção Os Pensadores).

GIACÓIA Jr., Oswaldo. A autossupressão como catástrofe da consciência moral. Estudos Nietzsche, Curitiba, v.I, n.I, p. 73-I28, jan./jun. 2010.

MACHEREY, Pierre. Introduction à l'éthique de Spinoza. La première partie, la nature des choses. Paris: PUF, 1997.

MARTINS, André. (org.). O mais potente dos afetos: Spinoza e Nietzsche. São Paulo: Martins Fontes, 2009.

NIETZSCHE, Friedrich. Aurora. Trad. Paulo Gésar de Souza. São Paulo: Companhia das Letras, 2004.

. Genealogia da moral. Trad. Paulo Gésar de Souza. São Paulo, Companhia das Letras, I998.

SANTIAGO,Homero. O filósofo espinosista precisa criar valores?. Trans/Form/ Ação, São Paulo, v. 30, n. I, 2007 a.

. O mais fácil e o mais difícil: a experiência e o início da filosofia. Revista Conatus - Filosofia de Spinoza, Fortaleza, v. I, n. 2, dez. 2007b. 
A crítica radical de Espinosa como autoproblematização

Superstição e ordem moral do mundo. In: MARTINS, André (Org.). O mais potente dos afetos: Spinoza e Nietzsche. São Paulo: Martins Fontes, 2009a. - Caderno de resumos, palestras, minicursos e comunicações. II Colóquio Internacional Benedictus de Espinosa, I6-20 nov., 2009b.

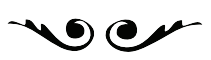

Dario Galvão - Graduando em Filosofia pela FFLGH - Universidade de São Paulo.

dario.neto@usp.com.br 